Gut, 1984, 25, 188-202

Progress report

\title{
Inflammatory bowel disease in childhood
}

Infants and children are not only growing but also developing, both physically and intellectually, and these differences embody the reasons why many diseases, of which inflammatory bowel disease is a good example, produce differing symptoms and management problems compared with adults. It is the aim of this review to highlight these differences rather than to provide a totally comprehensive account of inflammatory bowel disease in childhood.

The more important causes of inflammatory bowel disease in children are similar to those in adults with the exception of food allergy, which is an important and underestimated cause of colitis in infancy, and is discussed more fully later. As there is considerable controversy surrounding inflammatory bowel disease, many of the views in this study reflect our own experience and practice, which are essentially empirical and pragmatic where there are no scientifically well founded guidelines available.

\section{Incidence}

There is evidence from several centres that there has been a recent increase in the incidence of Crohn's disease. ${ }^{12}$ This increase has occurred in all age groups and in the United Kingdom, in contrast with ulcerative colitis, has been associated with a growing mortality rate. Between $18-33 \%$ of patients ${ }^{34}$ present before the age of 20 years, and therefore these figures must have important implications for the paediatric gastroenterologist. The increase in the number of referrals of children to the Hospital for Sick Children, London with Crohn's disease over the last few years has been such that an outpatient clinic devoted entirely to patients with inflammatory bowel disease has been established. Despite a remarkable increase in incidence, no single environmental factor has been shown to be the aetiological agent in Crohn's disease. ${ }^{5}$

In contrast with Crohn's disease, the incidence of ulcerative colitis has not changed ${ }^{2}$ so that the overall incidence of Crohn's disease and ulcerative colitis appears to be similar. As the proportion of patients with ulcerative colitis who present at under 20 years of age may be as low as half the corresponding figure for Crohn's disease, most paediatricians will probably see significantly more Crohn's disease than ulcerative colitis in the future.

\section{Clinical manifestations}

CROHN'S DISEASE

When Crohn's disease presents abruptly with the triad of abdominal pain, diarrhoea, and weight loss the diagnosis is usually made easily. Usually the 
onset of Crohn's disease is insidious, when the main symptoms and signs may be extra-intestinal (Table). Not surprisingly, the initial diagnosis made in children subsequently shown to have Crohn's disease is often incorrect (over one third are thought to have an infectious or connective tissue disorder ${ }^{7}$ ) and the correct diagnosis may be considerably delayed. The Johns Hopkins group have shown a mean delay of 13 months between onset of symptoms and diagnosis ${ }^{7}$ while delayed referral raises this figure to nearly three years in a series from St Bartholomew's Hospital, London. ${ }^{6}$

\section{ULCERATIVE COLITIS}

As in adults, ulcerative colitis usually presents with bloody diarrhoea although this is less commonly seen in children. ${ }^{8}$ While $60 \%$ of children present with mild diarrhoea of insidious onset with or without bleeding, $10 \%$ will present with a fulminating colitis, possibly with a toxic megacolon and require emergency treatment when first seen. ${ }^{9}$ Growth failure in ulcerative colitis is less common than in Crohn's disease but the clinical picture may still be dominated by extra-intestinal manifestations, in particular arthritis, erythema nodosum, or uveitis. ${ }^{10}$ It is important to remember that in childhood, liver disease may be the sole presenting feature of inflammatory bowel disease ${ }^{11}$ and therefore all children with liver disease of unknown aetiology should be investigated with respect to possible inflammatory bowel disease.

\section{Laboratory assessment}

Although laboratory findings such as hypoalbuminaemia or anaemia may alert the clinician to the diagnosis of inflammatory bowel disease in the absence of intestinal symptoms, laboratory investigations will usually be used to define the severity of disease or the nutritional status of the child. We have not found the erythrocyte sedimentation rate helpful in assessing disease severity, but measurement of serum albumin is a very useful guide to disease activity; in this context Lloyd-Still and Green ${ }^{12}$ have shown a close correlation between severity of disease and serum albumin

Table Symptoms in 32 patients with childhood Crohn's disease ${ }^{\circ}$

\begin{tabular}{lcc}
\hline Symptom & Presenting & Dominant \\
\hline Pain & 21 & 12 \\
Diarrhoea & 18 & 8 \\
Weight loss & 13 & 0 \\
Lassitude & 9 & 1 \\
Anorexia & 9 & 1 \\
Fever & 7 & 2 \\
Nausea/vomiting & 6 & 1 \\
Growth retardation & 6 & 2 \\
Erythema nodosum & 4 & 2 \\
Arthritis & 3 & 2 \\
Miscellaneous & & \\
$\quad$ Oedema (2) & & 1 \\
$\quad$ Perineal ulceration (1) & & \\
$\quad$ Uveitis (1) & & \\
Perineal abscess (1) & 7 & \\
Rectal haemorrhage (1) & & \\
Fissure-in-ano (1) & & \\
\hline
\end{tabular}


concentrations in children with inflammatory bowel disease. Similarly acute phase proteins may be helpful in assessing disease activity. ${ }^{13}$

\section{Colonoscopy}

With the advent of floppy, small diameter paediatric colonoscopes, colonoscopy now provides a safe, quick and accurate method of macroscopically and microscopically examining the entire colon in children, and does not require a general anaesthetic. ${ }^{14}$ As a result, the barium enema has been largely superseded. In a recent series of 123 consecutive colonoscopies in children ranging from 3 months to 16 years of age, examination of the whole colon was possible in all patients in which the colon was patent. ${ }^{14}$

Bowel preparation comprises clear fluids only for 24 hours before the examination, together with a large dose of senna syrup 15-20 hours pre-colonoscopy. Nearly all children have several large bowel actions after senna, but in the few in whom there is no response within 10 hours, a phosphate enema is administered, together with another enema one hour pre-colonoscopy which is also administered to all those children who do respond to senna. The procedure results in good preparation in over $90 \%$ of paediatric patients. In children, senna is preferable to mannitol, which requires the patient to drink $500 \mathrm{ml}$ fluid and often induces vomiting. Sedation is achieved with chlorpromazine $(1.5 \mathrm{mg} / \mathrm{kg}$ intramuscularly) one hour before the examination, together with slow intravenous diazepam (2-10 mg) and pethidine (10-50 mg) in doses titrated to achieve marked drowsiness but not total loss of consciousness. Naloxone must always be at hand to reverse the effects of pethidine if necessary. Although colonoscopic biopsies tend to be small and superficial, it is possible to make a firm diagnosis based on macroscopic, histological, and radiological findings in over $90 \%$ of children with inflammatory bowel disease. ${ }^{14}$ Colonoscopy is therefore mandatory in the diagnosis and management of inflammatory bowel disease in childhood, and the procedure should be performed in centres at which a skilled paediatric endoscopist is available.

Nazer $e t a l^{15}$ have recently shown that fibreoptic proctosigmoidoscopy can be performed in children without previous bowel preparation or sedation and with minimal discomfort. A highly flexible $1 \mathrm{~cm}$ diameter paediatric colonoscope was used and it was possible to take biopsies of sufficient size for adequate histological assessment in most cases. It seems likely that limited fibreoptic examinations which do not require the same skill and training needed for total colonoscopy, have an important role in the diagnosis and managemment of possible inflammatory bowel disease in children.

\section{Management}

In both ulcerative colitis and Crohn's disease, the aim is to induce and maintain remission, a result more readily achieved in ulcerative colitis than in Crohn's disease. Nutritional measures are extremely important in both diseases, particularly in Crohn's disease where the growth failure which occurs in $30 \%$ of children may respond favourably to the induction of nutritional repletion. ${ }^{16}$ 
The adoption of a team approach to the management of inflammatory bowel disease in children is important, with the involvement of physician, surgeon, psychiatrist, medical social worker, and stoma therapist.

\section{Crohn's disease}

DRUGS

To date, all controlled therapeutic trials have been performed in adults and the interpretation of many of the findings are somewhat controversial. As a result, the use of drugs in Crohn's disease in children is based on evidence obtained in adults, clinical acumen, and speculation (Figure). It is particularly important when treating childhood Crohn's disease, to bear in mind that in relatively quiescent disease the adverse effects of treatment may easily outweigh any benefit. Our current approach in patients presenting with symptomatic Crohn's disease (with the exception of those presenting with symptoms of perianal disease, oral disease or growth failure only) is to use prednisolone in a dose of $1-2 \mathrm{mg} / \mathrm{kg} / \mathrm{day}$ in the first instance. After induction of remission and/or symptomatic improvement, our aim would be to reduce the dose of prednisolone over four to six weeks followed by a complete cessation if possible. When long term corticosteroid therapy proves to be necessary in the growing child, there is a serious risk of iatrogenic growth retardation, although alternate day treatment may prevent this important side effect and maintain remission. ${ }^{17}$ In children with colonic involvement, it is our practice to use sulphasalazine in a dosage of $50-100 \mathrm{mg} / \mathrm{kg} /$ day beginning at the lower dosage, for one or two years, depending on the course of the disease.

While resolution of symptoms in Crohn's disease may follow treatment with azathioprine, ${ }^{18}$ good evidence to support its widespread use is equivocal. A recent double blind cross-over study has provided further

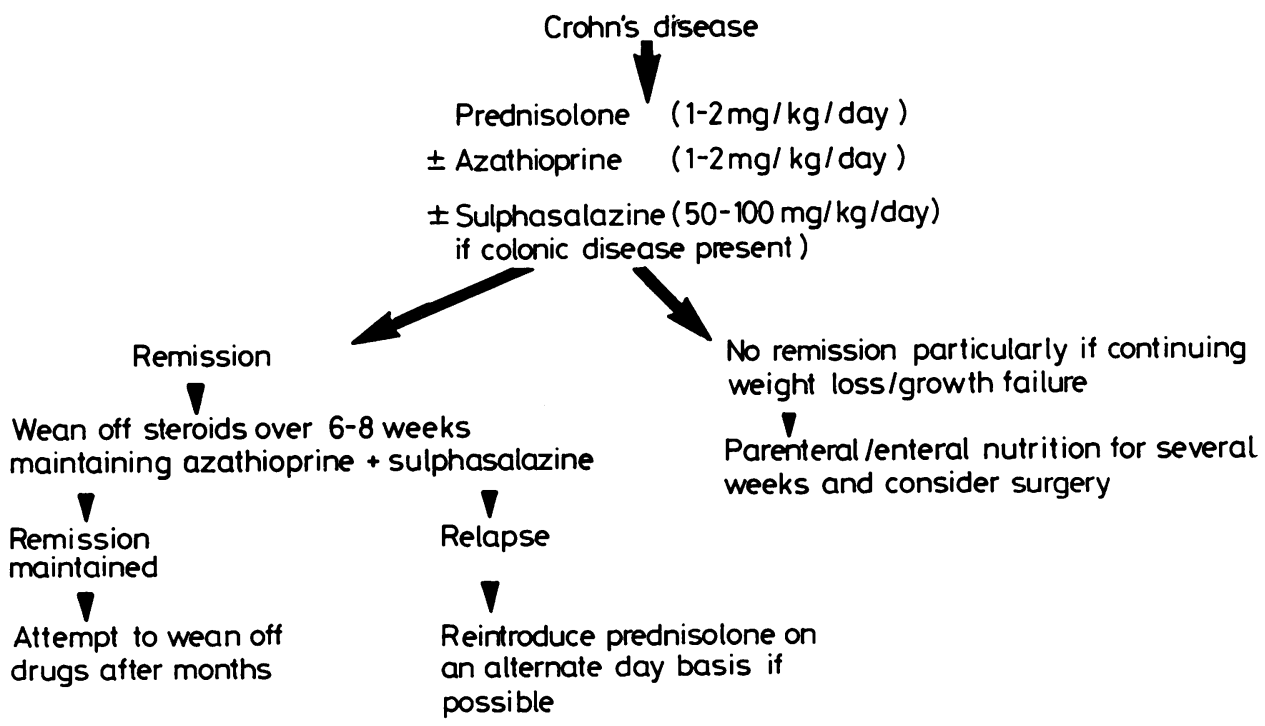

Figure Drug treatment of symptomatic Crohn's disease in childhood. 
evidence in support of immunosuppressive therapy, ${ }^{19}$ and our current practice is to use azathioprine in a dose of $1-2 \mathrm{mg} / \mathrm{kg} /$ day in children with symptomatic Crohn's disease. Treatment is begun at the same time as corticosteroids, and maintained after the reduction and probable cessation of steroids, in the hope that either remission may be prolonged in the absence of steroids or that azathioprine will exert a steroid sparing effect. The results of controlled trials of metronidazole are conflcting ${ }^{20-23}$ but in spite of this, occasional children, like adults, may benefit, particularly those with colonic or perianal lesions. ${ }^{2124}$

NUTRITIONAL SUPPORT

Nutritional support is important in two respects. Increased calorie and nitrogen intakes, possibly with resort to the parenteral route, may have a specific role not only in the management of the inflammatory process but also of growth failure. Secondly, nutritional measures have an important part to play in the restoration of specific nutritional deficits commonly seen in Crohn's disease.

\section{Reasons for poor nutritional status in Crohn's disease}

(1) Decreased intake: the caloric intake of children with Crohn's disease is commonly reduced. In a recent study mean caloric intake was found to be only $56 \%$ of that recommended for height and age, although protein intake was within normal limits. ${ }^{16}$ Reduced intake may result from anorexia and nausea associated with a severe systemic illness, bolus colic after food, or in some cases, zinc deficiency producing loss of taste sensation. ${ }^{25} 26$ (2) Impaired absorption: absorptive defects in children are well recognised ${ }^{27}$ and presumably result from a widespread mucosal abnormality, disordered motility, stagnant loops, fistulae, or resection. (3) Increased losses: increased losses of intestinal protein and blood are common, and result from extensive areas of intestinal ulceration and exudation. ${ }^{27}{ }^{28}$ Thus, faecal nitrogen excretion in children with Crohn's disease is raised compared with control subjects but is not increased after dietary supplementation, suggesting that this abnormality results from mucosal loss rather than true protein malabsorption. ${ }^{29}$ In addition during periods of catabolism large amounts of nitrogen are lost in the urine, particularly during treatment with corticosteroids. ${ }^{30} 31$

\section{Improvement of nutrition as primary treatment}

Improvement of nutrition by means of elemental diets and parenteral nutrition has been shown to be possible in inflammatory bowel disease in a large number of studies over the last 15 years. Experience with parenteral nutrition in adults has been reviewed by Driscoll and Rosenberg, ${ }^{32}$ and this form of management can induce a remission of symptoms in up to $80 \%$ of patients; however, the remission is often short lived and the number of patients remaining in remission three months later varies between $20 \%$ and $79 \%$. Experience in children using this form of treatment is limited. Strobel and colleagues ${ }^{33}$ have reported their experience of home parenteral nutrition in 17 paediatric patients, all of whom had severe, symptomatic Crohn's disease. All 17 patients showed weight gain and symptomatic improvement and 10 had catch up growth in height. A complete remission was obtained in 12 patients during the first course of 
parenteral nutrition lasting from 46 to 339 days and in four, this was long term. In those patients who had an early relapse, enteric protein loss was high after treatment whereas in those who went into long term remission it became normal, suggesting that this investigation may be of useful predictive value.

Our indications for parenteral feeding are severe malnutrition, patients in whom medical treatment has failed and who are unsuitable for surgery, and the improvement/maintenance of nutrition pre- and postoperatively. An additional indication, that of growth failure, will be considered separately below.

Elemental diets have also received a considerable amount of attention in the management of inflammatory bowel disease but to date most reported trials have been uncontrolled. Correction of malnutrition, anaemia, and hypoalbuminaemia together with induction of remission may be achieved $^{34-38}$ but there is no good evidence that nitrogen retention occurs more readily with elemental diets than with an isocaloric blenderised whole protein diet. ${ }^{39}$ O'Morain et $a l^{40}$ have recently provided important preliminary evidence to suggest that nutritional restitution, using an elemental diet, in patients with Crohn's disease in relapse is as equally effective in inducing remission as prednisolone 0.5 to $0.75 \mathrm{mg} / \mathrm{kg}$ body weight per day. Thus, while elemental diets are unpalatable and may precipitate diarrhoea in children, they provide not only a convenient method of achieving nutritional improvement but may also represent a means of inducing remission which is not associated with the potential hazards of steroid therapy.

Specific deficiencies

Iron deficiency, presumably related to diminished intake, malabsorption, and intestinal blood loss, is occasionally seen and should be differentiated from the normochromic anaemia seen in patients with chronic inflammatory disorders which is characterised by a low serum iron and total iron binding capacity. In addition to malabsorption, sulphasalazine therapy is an additional cause of folate deficiency. Although serum $\mathbf{B}_{12}$ levels are rarely low, $50 \%$ of children with Crohn's disease have impaired vitamin $B_{12}$ absorption as a result of terminal ileal disease. ${ }^{27}$

Zinc deficiency is probably common in Crohn's disease; McClain et al ${ }^{26}$ have reported low serum zinc concentrations in 21 out of 52 patients with Crohn's disease, with an associated depression of taste sensation and zinc absorption. Our experience in children is consistent with this finding, and low plasma concentrations of zinc are commonly found. As Aggett and Harries ${ }^{41}$ have pointed out, however, plasma concentrations of zinc are subject to acute variation and a single low value should not be interpreted as necessarily indicating zinc deficiency. It is our practice therefore to measure simultaneously the plasma activity of a zinc-dependent enzyme, such as alkaline phosphatase or carbonic anhydrase, which is depressed in zinc deficiency. It should be remembered that plasma concentrations of alkaline phosphatase activity in children vary with age and also with any concurrent vitamin D or calcium deficiency.

We have not so far observed the overt clinical manifestations of zinc deficiency in any of our patients with Crohn's disease, but the characteristic eczematous dermatitis around the eyes, nose and mouth, and on the 
perineum has been described in adults. ${ }^{26}$ Of importance in patients who may be malnourished and who may require parenteral feeding, is the impairment in cell mediated immunity seen in association with zinc deficiency. ${ }^{42}$ Although in malnourished, zinc deficient children, administration of zinc coincides with periods of rapid growth, ${ }^{43}$ the relationship between zinc deficiency, impaired taste sensation and growth failure in Crohn's disease has not been clearly defined. Measurement of plasma zinc and alkaline phosphatase activity should be performed in all patients with Crohn's disease and supplementation in the form of zinc sulphate provided in those in whom both these parameters are low.

\section{GROWTH FAILURE}

Growth retardation and delayed sexual development occurs in up to $30 \%$ of children and adolescents with Crohn's disease. ${ }^{74-46}$ In addition to posing very difficult management problems, growth failure may present difficult diagnostic problems, and may be the sole manifestation of disease in about $5 \%$ of patients. ${ }^{67}$ Furthermore, the growth failure of Crohn's disease may present a picture which is clinically indistinguishable from anorexia nervosa. ${ }^{47}$ Despite its frequency, the pathogenesis of the growth failure remains unclear. Low concentrations of growth hormone after insulin-induced hypoglycaemia have been reported ${ }^{45}$ but subsequent administration of human growth hormone did not produce any improvement in growth rate. ${ }^{48}$

More recently, nocturnal growth hormone secretion has been studied and found to be low in three out of five patients with growth retardation. ${ }^{49}$ Abnormalities in growth hormone secretion, however, were unrelated to the growth velocities of these patients, but did correlate with the disease activity score. In addition, abnormalities of gonadotrophin and follicle stimulating hormone secretion were present, suggesting depression of hypothalamic-pituitary function. These observations suggest that a primary endocrine cause for the growth failure of Crohn's disease is unlikely.

Corticosteroid therapy may contribute to growth failure, although paradoxically in some patients growth can accelerate when disease activity is suppressed by steroids. ${ }^{17}$ Although malabsorption and zinc deficiency may play a part in the pathogenesis of growth failure, there is accumulating evidence that nutritional deprivation is the most important single determinant of growth failure in Crohn's disease. ${ }^{50}$ Body weight is characteristically appropriate for height, ${ }^{44} 50$ strongly suggesting that affected children are in fact 'nutritional dwarfs' ${ }^{51}$ In children with chronic renal insufficiency, reduced growth velocity occurs if caloric intake is reduced below $80 \%$ of that recommended for the child's age, and ceases altogether if intake falls to below $40 \% .^{52}$ Do growth retarded children with Crohn's disease then have diminished caloric intakes? The answer to this question is probably yes, because mean values of $56 \%$ and $82 \%$ of recommended daily intake have been recorded in published series. ${ }^{16} 50$ What then is the effect of calorie and protein supplementation upon subsequent growth?

Two groups have studied the effect of parenteral nutrition on growth. ${ }^{58}$ In the group of seven patients treated by Kelts et al, ${ }^{50}$ an eight week period of parenteral nutrition was associated with an increase in the annual growth velocity from a mean of $32 \%$ of that expected for bone age 
to one of $108 \%$ one year after therapy. Such an extended period of growth after a short period of parenteral nutrition is particularly interesting and it is tempting to speculate that had the improved nutritional intake been maintained for longer, true 'catch-up' growth might have been achieved. From these studies it can be concluded that chronic protein calorie malnutrition consequent upon an impaired intake plays an important role in the pathogenesis of growth failure in Crohn's disease.

Must nutritional supplementation be given by the intravenous route? The answer to this question is no. Four children, described by Morin et $a l,{ }^{54}$ with long standing growth retardation, received a six week course of an elemental diet delivered by intragastric infusion. All four children experienced remission of symptoms, improved nutritional status and a significant increase in weight and height. Three out of the four children continued to grow until the disease relapsed; the fourth child required surgery two months after cessation of treatment but subsequently showed accelerated growth.

Kirschner and colleagues ${ }^{16}$ have shown that nutritional supplementation need not be in elemental form to improve growth. During a follow-up period of four years, the calorie intake in seven children was boosted from $56 \%$ of recommended to $91 \%$ of that recommended for height. Improvement in growth was such that five children came within $5 \%$ of their pre-illness height centile. In each patient, food intake was supplemented by an elemental diet for up to the first 12 months of the study, but thereafter six of the seven children received no artificial supplementation. These results emphasise firstly the importance of nutritional depletion as a cause of growth failure, and secondly the importance of nutritional supplementation with conventional foodstuffs in improving growth.

Motil et $\mathrm{al}^{29}$ have recently performed an elegant study on six adolescents suffering from growth failure secondary to Crohn's disease, in which the mechanisms by which increases in lean body mass after dietary supplementation were investigated. Lean body mass (measured by whole body ${ }^{40} \mathrm{~K}$ estimation and urinary creatinine), $\left({ }^{13} \mathrm{C}\right)$ leucine metabolism and nitrogen balance were studied before and during the third week of a $40 \%$ increase in dietary protein and energy. Dietary supplementation resulted in a fourfold increase in daily nitrogen balance, a significant increase in total body ${ }^{40} \mathrm{~K}$ and a very rapid weight gain. These changes were accounted for by not only a $66 \%$ increase in the rate of $\left({ }^{13} \mathrm{C}\right)$ leucine incorporation into body protein but also and remarkably by a $41 \%$ decrease in leucine oxidation.

Homer and Grand ${ }^{44}$ have assessed the role of surgery in the primary management of growth failure, and have shown that it has a place only in the completely prepubertal child in whom all macroscopically abnormal bowel can be resected. If these criteria cannot be met, then it seems that the growth response to surgery alone may be disappointing.

SURGERY

We reserve surgery for the complications of Crohn's disease such as obstruction, toxic megacolon, fistulae and abscesses, together with those children whose symptoms, particularly if associated with growth failure, do not respond to medical treatment. Perianal disease is rarely sufficiently severe enough to require proctectomy and can usually be managed 
conservatively, sometimes with drainage of abscesses.

Younger patients have an increased rate of recurrence as defined by the need for a definitive surgical procedure, compared with adults; ${ }^{55}$ those under 20 years of age have a probable recurrence rate of $70 \%$ compared with $30 \%$ over 40 years, showing the more aggressive nature of Crohn's disease in the paediatric population. ${ }^{56}$

Crohn's colitis in childhood can present special problems in management. Local complications such as fistulae and abscesses, and systemic complications such as arthritis or erythema nodosum are common as are postoperative problems. ${ }^{57}$ In a group of 25 children, followed for a mean of 17 years, 17 patients required 74 operations, including 45 major definitive procedures. In eight of the children, disease extended proximally into the ileum over periods ranging from a few weeks to 11 years. ${ }^{57}$

\section{Ulcerative colitis}

In many respects management of ulcerative colitis in childhood presents fewer problems than Crohn's disease, in that diagnosis is easier, proctocolectomy is curative, medical treatment is more clearly defined, and growth retardation much less common. Children are more likely to have active and more extensive disease than adults however, with $90 \%$ having moderate to severe disease. ${ }^{58}$ There may be a higher risk of malignancy, ${ }^{59}$ possibly as a result of more extensive colitis or of longer exposure to the disease.

DRUGS

Topical and systemic steroids together with sulphasalazine are used in children in the same manner as in adults. Administration of long term corticosteroids on an alternate day basis may lessen growth suppression ${ }^{17}$ but a child requiring a dose sufficiently high to produce significant side effects usually benefits from a colectomy.

FULMINATING ATTACK

In our experience, the severity of fulminating colitis in childhood is easily underestimated by inexperienced physicians and as a result referral to an experienced centre delayed. Treatment with intravenous fluids and electrolytes will be necessary in all patients and most will require blood transfusion and frequent albumin infusions. It should be emphasised that emergency surgery on children in the presence of a low serum albumin, and consequently a low circulating plasma volume, is a particularly hazardous undertaking. All patients will require parenteral steroids and this is given as hydrocortisone, $10 \mathrm{mg} / \mathrm{kg} / \mathrm{day}$ or alternatively as prednisolone, $2 \mathrm{mg} / \mathrm{kg} / \mathrm{day}$, which produces less sodium retention. In addition, most patients receive broad-spectrum intravenous antibiotics, usually penicillin, gentamicin and metronidazole, but their use is largely empirical.

Werlin and Grand have reviewed their experience with 19 children with fulminant colitis, ${ }^{60}$ six of whom were having their first attack. Ten required early surgery because of failed medical treatment, massive bleeding, colonic perforation, or toxic megacolon. Of the remaining nine, five required colectomy within the subsequent two years. Three had chronic debilitating disease and only one remained in remission. Thus, one third of 
the children responded rapidly to medical treatment but their remission was short lived and the majority came to surgery sooner rather than later.

TOXIC MEGACOLON

The development of a toxic megacolon in children may occur in the absence of gross colonic dilatation; at its widest part, usually the transverse colon and splenic flexure in this condition, it may be only $4 \mathrm{~cm}$ in diameter. We do not therefore place undue emphasis on absolute measurements when making the diagnosis of toxic megacolon in children. In the series by Werlin and Grand, ${ }^{60}$ this severest of all complications developed in three out of 19 patients with severe colitis. In our experience, every child developing a toxic megacolon has come to early surgery within 48 to 72 hours, and it is important to prepare parents and child for this eventuality early in the course of a fulminating illness.

\section{SURGERY}

In an emergency, the indications for surgery are relatively clearly defined but the precise timing of an elective colectomy is a much more difficult decision. Against the possible psychosocial effects of an ileostomy upon the child and his family, the dangers of delaying surgery must be considered: continuing chronic ill health and loss of schooling, the cumulative effects of long term drug therapy and the risk of cancer, which is associated with a lower survival rate in the younger patient. ${ }^{61}$ The question of prophylactic colectomy versus two yearly colonoscopy is difficult to answer although the greater life expectancy of young patients and the availability of a continent ileostomy suggest that surgery may be preferable. It is very important to prepare the child and parents psychologically before colectomy and once again we would stress the importance of a team approach. Most surgeons treating adults would advise proctocolectomy and ileostomy in the majority of cases. ${ }^{62}$ Some paediatric surgeons, however, have an impression that children tend to manage better with an ileo-rectal anastomosis than do adults, and diarrhoea is not a problem. ${ }^{63}$ There is a good argument in favour of attempting to carry a child through the critical period of puberty and adolescence without an ileostomy. In those children who do require proctocolectomy and ileostomy, however, it is our impression that when appropriately prepared for surgery, they manage surprisingly well with a stoma.

What of alternative surgical procedures? We believe that there are few indications for ileo-anastomy. Diarrhoea is usually profuse and excoriating and the only indication appears to be in very strongly motivated patients who are repelled by an ileostomy ${ }^{63}$ and in this context, a continent ileostomy may be useful. ${ }^{64-66}$ Maintenance of sphincters and anorectal continence is possible, using a variety of pull through operations ${ }^{67}$ and encouraging results have been reported in a group of paediatric patients. ${ }^{68}$

\section{Food allergy}

In contrast with colitis occurring in adults and older children, food allergy appears to play an important aetiological role in colitis in infancy and accounts for what was previously thought to be an increased incidence of 
ulcerative colitis in the first year of life compared to later childhood. Eight such infants have been seen at the Hospital for Sick Children over the last three years in whom the introduction of artificial feeding coincided with the onset of bloody diarrhoea which in some cases was severe. ${ }^{69}$ Six of the eight infants presented at less than 4 months of age and in each case there was a prompt remission of symptoms when an antigen exclusion diet was introduced. Cow's milk protein was the most common offending antigen but sensitivity to soya protein and beef were also shown. These patients tend to be characterised by a strong family history of atopy, eczema, the presence of IgE anti-cow's milk antibodies and eosinophilia, and at colonoscopy the macroscopic appearance of the colon is indistinguishable from ulcerative colitis. As there is a marked increase in eosinophils in the lamina propria, colonoscopy with biopsies is an important tool in differentiating this condition from true ulcerative colitis and Crohn's disease, both of which may rarely occur during the first year of life. Provided the condition is recognised and appropriately treated with an exclusion diet, the prognosis appears to be excellent.

\section{Prognosis}

\section{CROHN'S DISEASE}

The site of the disease is an important determinant of long term outcome. In terms of extra-intestinal symptoms such as growth failure, operative rate, and response to medical treatment, children with ileocolitic lesions fare worst, and children with isolated small bowel disease not involving the duodenum best. ${ }^{70}$

Patients under 20 years of age have not only a high recurrence rate, but also a significantly higher mortality rate than their older counterparts, particularly in the first few years after diagnosis. ${ }^{71}$ It is now generally agreed that adenocarcinoma of the large and small bowel occurs with greater frequency, but the exact risks require better definition. ${ }^{72}$ In our experience and that of others, ${ }^{73}$ however, an optimistic attitude is justified in that most children lead normal lives for most of the time, experience good general health and do not miss large amounts of schooling.

\section{ULCERATIVE COLITIS}

In a large retrospective study from the Mayo Clinic ${ }^{74}$ covering the period 1919-1965, it was found that total colitis beginning in childhood was associated with a mortality of $20 \%$ per decade. After the first decade, the risk of developing cancer was also $20 \%$ per decade. As has been pointed out recently, ${ }^{1}$ however, this group of patients was likely to have had severe colitis and were managed in an era when colectomy was unusual, and it seems likely that the current extent of cancer related mortality is considerably less than that reported from the Mayo. ${ }^{61}$

\section{Psychosocial support}

Inflammatory bowel disease in childhood often presents the child and family with many years of chronic ill health, and multiple visits to hospital. In Crohn's disease in particular, the disease is often at its most aggressive in the years immediately after onset and it is under these circumstances 
that a team approach should be adopted, with physician, psychiatrist, social worker, clinical psychologist, and nursing staff pooling their resources in order to support the child and his family. Not only will this type of approach improve the patient's sense of well being but may also reduce the number of relapses in ulcerative colitis. While we do not feel that psychological factors play any part in the pathogenesis of this disease, we have a strong impression that relapses may sometimes be linked to stressful life events.

Marked changes in mood, behaviour, outlook, and personality occur during adolescence with such frequency in the healthy that they are regarded as physiological. A newfound self and sexual awareness coupled with a need to rebel against all authority figures means that all patients in this age group require special handling. This is particularly true of patients with inflammatory bowel disease where chronic illness and also perhaps a stoma or growth failure, hinder close identification with their peer group. New problems such as poor drug compliance or erratic outpatient attendance are likely to arise, and a formal authoritarian approach on the part of the attending doctor is unlikely to be successful. The timing of the transfer of care of adolescent patients from the paediatric gastroenterologist to a colleague specialising in adults requires careful consideration in every case. It is usually best avoided until the problems of adolescence have subsided and in any case, the decision is made in close consultation with the patient.

While adolescent patients require sympathetic handling and extra support, so do their parents. Most parents find it difficult to relinquish the responsibility for the care of a sick child to the patient himself, particularly when the patient shows little interest in self-care, and many parents require extra help while undergoing this difficult process.

Another important source of support for patients with inflammatory bowel disease are self-help groups. In the United Kingdom for instance, the National Association for Colitis and Crohn's Disease* provides information on these diseases and, through its newsletters and meetings, allows patients to share and compare their experiences as well as increasing their knowledge about their disease.

IWB gratefully acknowledges financial support from the Eden Research Trust of the Royal College of Physicians of London.

Department of Child Health

I W BOOTH AND J T HARRIES $†$

Institute of Child Health

London and

The Hospital for Sick Children

Great Ormond Street

London

* 3 Thorpefield Close, Marshalswick, St Albans, Herts.

+ Professor Harries died on 27 March 1983. 


\section{References}

1 Mayberry J, Rhodes J, Hughes LE. Incidence of Crohn's disease in Cardiff between 1934 and 1977. Gut 1979; 20: 602-8.

2 Mendeloff AI. The epidemiology of inflammatory bowel disease. Clin Gastroenterol 1980; 9: 259-70.

3 Kyle J. Crohn's disease. New York: Appleton-Century-Crofts, 1972.

4 Banks BM, Zetzel L, Richter HS. Morbidity and mortality in regional enteritis. Report of 168 cases. Am J Dig Dis 1969; 14: 369-79.

5 Sachar DB, Auslander MO, Walfish JS. Aeotiological theories of inflammatory bowel disease. Clin Gastroenterol 1980; 9: 231-57.

6 O'Donoghue DP, Dawson AM. Crohn's disease in childhood. Arch Dis Child 1977; 52: 627-32.

7 Burbige EJ, Shi-Shung Huang, Bayless TM. Clinical manifestations of Crohn's disease in children and adolescents. Paediatrics 1975 ; 55: 866-71.

8 Michener WM. Ulcerative colitis in children: problems in management. Paediatr Clin North Am 1967; 14: 159-73.

9 Grand RJ, Homer DR. Approaches to inflammatory bowel disease in childhood and adolescence. Paediatr Clin North Am 1975; 22: 835-50.

10 Greenstein AJ, Janowitz HD, Sachar DB. The extra-intestinal complications of Crohn's disease and ulcerative colitis: a study of 700 patients. Medicine 1976; 55: 401-12.

11 Kane W, Miller K, Sharp HL. Inflammatory bowel disease presenting as liver disease during childhood. J Paediatr 1980; 97: 775-8.

12 Lloyd-Still JD, Green OC. A clinical scoring system for chronic inflammatory bowel disease in children. Dig Dis Sci 1979; 24: 620-4.

13 Campbell CA, Walker-Smith JA, Hindocha P, Adinolfi M. Acute phase proteins in chronic inflammatory bowel disease in childhood. J Pediatr Gastroenterol Nutr 1982; 1: 193-202.

14 Williams CB, Laage NJ, Campbell CA, Douglas JR, Walker-Smith JA, Booth IW, Harries JT. Total colonoscopy in childhood. Arch Dis Child 1982; 57: 49-53.

15 Nazer H, Walker-Smith JA, Davidson K, Williams CB. Outpatient paediatric fibreoptic proctosigmoidoscopy: possible and useful. $\mathrm{Br}$ Med J 1983; 00: 000-00.

16 Kirschner BS, Klich JR, Kalman SS, de Favaro MV, Rosenberg IH. Reversal of growth retardation in Crohn's disease with therapy emphasising oral nutritional restitution. Gastroenterology 1981; 80: 10-15.

17 Whittington PF, Barnes HV, Bayless IM. Medical management of Crohn's disease in adolescence. Gastroenterology 1977; 72: 1338-44.

18 Harries JT, Lloyd J. Azathioprine in the treatment of Crohn's disease. Acta Paediatr Scand 1970; 60: 376.

19 Present DH, Korelitz BI, Wisch N, Glass JL, Sachar DB, Pasternack BS. Treatment of Crohn's disease with 6-mercaptopurine. $N$ Engl J Med 1980; 302: 981-7.

20 Ursing B, Kamme C. Metronidazole for Crohn's disease. Lancet 1975; 1: 775-7.

21 Allan R, Cooke WT. Evaluation of metronidazole in the management of Crohn's disease. [Abstract] Gut 1977; 18: A422.

22 Sachar DB. Metronidazole for Crohn's disease - breakthrough or ballyhoo? Gastroenterology 1980; 79: 393-5.

23 Hildebrand H, Berg NO, Hoevels J, Ursing B. Treatment of Crohn's disease with metronidazole in childhood and adolescence. Gastroenterol Clin Biol 1979; 4: 19-25.

24 Brandt LJ, Bernstein LH, Boley SJ, Frank MS. Metronidazole therapy for perirenal Crohn's disease: a follow-up study. Gastroenterology 1982; 83: 383-7.

25 Hambidge KM, Hambidge C, Jacobs M, Baum JD. Low levels of zinc in hair, anorexia, poor growth and hypogeusia in children. Pediatr Res 1972; 6: 868-74.

26 McClain C, Soutor C, Zieve L. Zinc deficiency: a complication of Crohn's disease. Gastroenterology 1980; 78: 272-9.

27 Beeken WL. Absorptive defects in young people with regional enteritis. Pediatrics 1973; 52: $69-74$

28 Morson BC, Dawson IMP. Gastrointestinal pathology. 2nd ed. Oxford: Blackwell Scientific Publications, 1979.

29 Motil KJ, Grand RJ, Matthews DE, Bier DM, Maletskos CJ, Young VR. Whole body leucine metabolism in adolescents with Crohn's disease and growth failure during nutritional supplementation. Gastroenterology 1982; 82: 1359-68.

30 Foster KJ, Karran SJ. The role of hormones in intravenous feeding. In: Karran SJ, Alberti 
KG, eds. Practical nutritional support. London: Pitman Medical, 1980: 149-59.

31 Haynes RC, Murad F. Adrenocorticotrophic hormone; adrenocortical steroids and their synthetic analogues; inhibitors of adrenocortical steroid biosynthesis. In: GoodmanGilman A, ed. Pharmacological basis of therapeutics. London: Macmillan, 1980: 1474.

32 Driscoll RH, Rosenberg IH. Total parenteral nutrition in inflammatory bowel disease. Med Clin North Am 1978; 62: 185-201.

33 Strobel CT, Byrne WJ, Ament ME. Home parenteral nutrition in children with Crohn's disease: an effective management alternative. Gastroenterology 1979; 77: 272-9.

34 Axelsson C, Jarman S. Assessment of the therapeutic value of an elemental diet in chronic inflammatory bowel disease. Scand J Gastroenterol 1977; 12: 89-95.

35 Goode A, Hawkins T, Teggetter JGW Johnston IDA. Use of an elemental diet for long term nutritional support in Crohn's disease. Lancet 1976; 1: 122-4.

36 O'Morain C, Segal AW, Levi AJ. Elemental diets in treatment of acute Crohn's disease. Br Med J 1980; 281: 1173-5.

37 Morin CL, Roulet M, Weber A, Roy CC, Lapointe N. Nasogastric infusion of elemental diet as primary therapy in Crohn's disease. Pediatr Res 1979; 13: 405.

38 O'Morain CA, Segal AW, Levi AJ, Valman HB. Elemental diet in acute Crohn's disease. Arch Dis Child 1983; 53: 44-7.

39 Moriarty KJ, Hegarty JE, Clarke M, Fairclough PD, Dawson AM. A comparison of the relative nitrogen-sparing properties of whole protein, protein hydrolysate, and the equivalent amino acid mixture in man. Gastroenterology 1981; 80: 1234.

40 O'Morain CA, Segal AW, Levi AJ. Elemental diets in the treatment of acute Crohn's disease: a controlled study. [Abstract] Gut 1982; 23: A891.

41 Aggett PJ, Harries JT. Current status of zinc in health and disease states. Arch Dis Child 1979; 54: 909-17.

42 Golden MHN, Golden BE, Harland PSEG, Jackson AA. Zinc and immunocompetence in protein-energy malnutrition. Lancet 1978; 1: 1226-27.

43 Golden MNH, Golden BE. Trace elements: potential importance in human nutrition with particular reference to zinc and vanadium. Br Med Bull 1981; 37: 31-6.

44 Homer DR, Grand RJ, Colodny AH. Growth, course and prognosis after surgery for Crohn's disease in children and adolescents. Pediatrics 1977; 59: 717-25.

45 McCaffery TD, Nasr K, Laurence AM, Kirsner JB. Severe growth retardation in children with inflammatory bowel disease. Pediatrics 1970; 45: 386-93.

46 Kirschner BS, Voinchet O, Rosenberg IH. Growth retardation in inflammatory bowel disease. Gastroenterology 1978; 75: 504-11.

47 Gryboski JD, Katz J, Sangree MH, Herskowic T. Eleven adolescent girls with severe anorexia: intestinal disease or anorexia nervosa. Clin Pediatr 1968; 7: 684-90.

48 McCaffery TD, Nasr K, Laurence AM, Kirsner JB. Effect of administered human growth hormone on growth retardation in inflammatory bowel disease. J Dig Dis 1974; 9: 411-6.

49 Farthing MJG, Campbell CA, Walker-Smith JA, Edwards CRW, Rees LH, Dawson AM. Nocturnal growth hormone and gonadotrophin secretion in growth retarded children with Crohn's disease. Gut 1981; 22: 933-8.

50 Kelts DG, Grand RJ, Shen G, Watkins JB, Werlin SL, Boehme C. Nutritional basis of growth failure in children and adolescents with Crohn's disease. Gastroenterology 1979; 76: 720-7.

51 Waterlow JC. Classification and definition of protein calorie malnutrition. Br Med J 1972; 3: $566-9$.

52 Betts PR, Magrath G. Growth pattern and dietary intake of children with chronic renal insufficiency. Br Med J 1974; 2: 189-93.

53 Layden T, Rosenberg J, Nemchausky B, Elson C, Rosenberg I. Reversal of growth arrest in adolescents with Crohn's disease after parenteral alimentation. Gastroenterology 1976; 70: 1017-21.

54 Morin CL, Roulet M, Roy CC, Weber A. Continuous elemental enteral alimentation in children with Crohn's disease and growth failure. Gastroenterology 1980; 79: 1205-10.

55 Cooke WT, Mallas E, Prior P, Allan RN. Crohn's disease: course, treatment and long term prognosis. $Q J$ Med 1980; 49: 363-84.

56 Cooke WT. Factors in the management of Crohn's disease: a discussion paper. J Roy Soc Med 1981; 74: 753-8.

57 Korelitz BI, Gribetz D, Kopel FB. Granulomatous colitis in children: a study of 25 cases and comparison with ulcerative colitis. Pediatrics 1968; 42: 446-57.

58 Ament ME. Inflammatory disease of the colon: ulcerative colitis and Crohn's colitis. $J$ Pediatr 1969; 86: 322-34. 
59 Devroede G, Taylor WF. On calculating cancer risk and survival in ulcerative colitis patients with the life table method. Gastroenterology 1976; 71: 505-9.

60 Werlin SL, Grand RJ. Severe colitis in children and adolescents: diagnosis, course and treatment. Gastroenterology 1977; 73: 828-32.

61 Butt JH, Lennard-Jones JE, Ritchie JK. A practical approach to the risk of cancer in inflammatory bowel disease. Med Clin North Am 1980; 64: 1203-20.

62 Alexander-Williams J, Buckmann P. Criteria of assessment for suitability and results of ileorectal anastomosis. Clin Gastroenterol 1980; 9: 409-17.

63 Nixon HH. Surgical conditions in paediatrics. London: Butterworth, 1978.

64 Koch NG. Intra-abdominal 'reservoir' in patients with permanent ileostomy. Arch Surg 1969; 99: 223-30.

65 Koch NG. Continent ileostomy. Prog Surg 1973; 12: 180-201.

66 Parks AG, Nicholls RJ. Proctocolectomy without ileostomy for ulcerative colitis. Br Med $J$ 1978; 2: 85-8.

67 Ravitch MM, Sabiston DC. Anal ileostomy with preservation of the sphincter. Surg Gynecol Obstet 1947; 84: 1095-9.

68 Martin LW, Le Coultre C, Schubert WK. Total colectomy and mucosal proctectomy with preservation of continence in ulcerative colitis. Ann Surg 1977; 186: 477-80.

69 Jenkins HR, Milla PJ, Pincott JR, Soothill JF, Harries JT. Food allergy: the major cause of infantile colitis? [Abstract] Gut 1982; 23: A924.

70 Gryboski JD, Spiro HM. Prognosis in children with Crohn's disease. Gastroenterology 1978; 74: 807-17.

71 Mayberry FJ, Newcombe PG, Rhodes J. Mortality in Crohn's disease. $Q$ J Med 1980; 49: 63-8.

72 Lightdale CJ, Winaver SJ. More on carcinoma complicating Crohn's disease. Gastroenterology 1981; 81: 814-9.

73 Puntis J, McNeish AS, Allan RN. Impact of Crohn's disease in childhood. [Abstract] Gut 1982; 23: A892.

74 Devroede GJ, Taylor WF, Sauer W, Jackman RG, Stickler GB. Cancer risk and life expectancy of children with ulcerative colitis. $N$ Engl J Med 1971; 285: 17-21. 